\title{
The use of the first industrial X-ray CT scanner increases the lumber recovery value: case study on visually strength-graded Douglas-fir timber
}

\author{
Andreas Rais ${ }^{1}$ - Enrico Ursella ${ }^{1}$ - Enrico Vicario ${ }^{1}$ - Federico Giudiceandrea ${ }^{1}$
}

Received: 4 January 2017 / Accepted: 10 March 2017 / Published online: 3 April 2017

(C) INRA and Springer-Verlag France 2017

\begin{abstract}
- Key message Industrial computed tomography scanning of logs provides detailed information on timber quality prior to sawing. A sawing simulation-considering log rotation angle and knot size accuracy-revealed an average value increase of up to $20 \%$ for the best angle compared to the conventional horns-up position.

- Context Computed tomography (CT) scanning has the potential to improve the value of products sawn from logs and meets the increasing demands of the wood industry for detailed information on log quality prior to processing.

- Aims In a validation step, automated measurements of knot cluster variable DAB (DIN 4074-1:2012-06) using CT were compared with manual measurements. In a second optimization step, the hypothesis that the value of the sawn products is
\end{abstract}

Handling Editor: Jean-Michel Leban

Contribution of the co-authors Andreas Rais collected the data, run the data analysis and wrote the paper; Enrico Ursella strongly participated in the data analysis, contributed to the manuscript writing and developed the industrial CT scanner used; Enrico Vicario supported the sawing simulation as member of the development team; and Federico Giudiceandrea supervised the work, revised the manuscript and was responsible for the development of the industrial CT scanner for logs.

Andreas Rais

andreas.rais@microtec.eu

Enrico Ursella

enrico.ursella@microtec.eu

Enrico Vicario

enrico.vicario@microtec.eu

Federico Giudiceandrea

federico.giudiceandrea@microtec.eu

1 Microtec srl, Via Julius-Durst 98, 39042 Bressanone, Italy increased by sawing at the best rotation angle as opposed to the horns-up position was tested.

- Methods A sample of 36 Douglas-fir logs were scanned in an industrial CT scanner, and sawn into boards. Knots on the boards were manually measured, and compared with the corresponding knots on virtual boards created from the $\mathrm{CT}$ data. The error of the DAB was measured by comparing CT data to manual measurements. An optimized sawing simulation was performed, using the measured DAB error to account for $\mathrm{CT}$ measurement errors, as well as a rotational error to account for errors in the log turning equipment. Using the results of the sawing simulation, Monte Carlo simulations were performed to show the potential and benefit of an industrial CT scanner. - Results The three largest DABs measured by the CT showed good correlation to the measurements on the manual boards. The simulation revealed an average increase of value from 4 to $20 \%$ compared to the conventional horns-up position depending on the relative price differences between the strength grades.

- Conclusion By using a CT scanner to optimize sawing, sawmill owners can process logs in a better way to produce final products with increased added value.

Keywords Breakdown optimization · Wood scanning $\cdot$ Log grading $\cdot$ Wood quality $\cdot$ Cutting pattern $\cdot$ Rotation angle

\section{Introduction}

1.1 CT to respond to the increasing future demands on wood products

Quality requirements of the wood market on the final product are continuously increasing. To adapt to these changing conditions, new approaches have been implemented in 
automation and optimization, based on non-destructive wood quality analysis and grading.

In recent years, new methods have been established to predict internal properties of the wood in each stem. In particular, computed tomography (CT) assists in ensuring wood is used for its best possible application and destination. Due to recent advances is computer processing and image analysis, CT enables the fast, accurate and detailed acquisition of a large amount of information about internal structures of objects. An overview of the history, research and publications of CT scanning of logs has been given by Wei et al. (2011). Pioneering research was done by Taylor et al. (1984), Funt and Bryant (1987), Grundberg (1999), Oja et al. (1998), Oja (2000), Nordmark (2005) and Brännström (2009) on medical CT scanners.

In general, computed tomography of logs can be used for both log sorting as well as optimization of the cutting pattern (Brännström 2009). In terms of log sorting, the assessment of log quality helps to sort the wood resource prior to processing, providing a more effective usage of timber. Consequently, significant savings of time and money can be realized and potentially valuable wood waste can be reduced, by preventing low-quality logs from being further sorted and handled, and preventing low-quality timber from being sawn or dried.

Regarding optimization of the cutting pattern, CT technology provides a complete reconstruction of the internal features of each log during sawmill processing. With this information, many new opportunities of segregation and cutting optimization are possible.

\subsection{Improving sawn timber yield by rotation angle}

The ongoing research aims at demonstrating the increase in sawn timber value that is possible by modifying rotation angle in the primary breakdown. Previous investigations have dealt with the optimal rotational position based on CT data (Fredriksson 2014; Breinig 2014), all of which underline the potential value increase when applying the log rotation. Value recovery is a function of both volume and quality. Focusing on volume recovery, Lundahl and Grönlund (2010) showed that the average volume yield can be increased by choosing an optimal rotation position. Additionally, they took into account the parallel positioning (displacement) of logs that is - in addition to the rotation and the skew - one of the three types of $\log$ positioning affecting the search for optimal solution. Wessels (2009), Berglund et al. (2013) and Breinig (2014) analysed the impact of horns-up position on volume recovery in more detail.

The value recovery can be improved by taking internal wood features into account. Internal feature detection requires the application of a CT scanner, whereas the outer shape can sufficiently be determined and described by a 3D scanner. For appearance and strength grading, the most important internal wood features are the position and size of knots. In addition to measuring many other internal features, such as cracks and pitch pockets, a CT scanner can take into account the location and size of knots for the optimization of $\log$ breakdown.

Berglund et al. (2013) observed a mean value increase of about $13 \%$ for both Scots pine (Pinus sylvestris L.) and Norway spruce (Picea abies), if the rotation angle was optimized using internal information. The horns-up position served again as the reference. Other studies focused on hardwood and found also an increase in sawmill yield (Chang and Gazo 2009; Stängle et al. 2015).

\subsection{Objectives}

The study had two objectives:

- By comparing machine and manual data, to validate the precision of the knot variable DAB (DIN 4074-1:2012-06) predicted by an industrial CT scanner

- To quantify the increase in sawn boards' value when using the knowledge of the internal knottiness measured by the $\mathrm{CT}$ scanner prior to sawing

The second objective compares the standard horns-up position with the optimal log rotation calculated using the CT scanner. A rotational accuracy, to account for errors in log turning, and an accuracy for the knot variable DAB, taken from the first objective, are taken into account.

\section{Material and methods}

The logs used in this analysis were a subsample of Douglas-fir (Pseudotsuga menziesii [Mirb.] Franco) logs originating from trees in two experimental plots in Southern Germany. More details about their silvicultural treatment and site conditions are given in Rais et al. (2014b, c). The sampled wood represented young thinning trees of log dimensions usually sawn for structural timber. The grades of the sawn boards are summarized in Table 1 . The relatively low yield of high strength grades was in part caused by the trees' age of 40 years and corresponding high proportion of juvenile wood, as well as the fact that only centre boards were used for the ongoing investigation (Table 1). The average volume proportion of juvenile wood was $68 \%$ (standard deviation $18 \%$, minimum value $41 \%$, maximum value $100 \%$ ) for the sample. The proportion is based on stem discs that were cut out of the tree at both ends of each $\log$ (see Fig. 2 in Rais et al. (2014a)). Tree ring widths were measured to the nearest $1 / 100 \mathrm{~mm}$ in the four cardinal direction with a Digital Positiometer (Kutschenreiter and Johann; Digital positiometer, Biritz and Hatzl GmbH, 
Table 1 Log and board characteristics

$\begin{array}{lc}\text { Logs } & 36 \\ n_{\text {log }} & 4.1 \\ \text { Length in } \mathrm{m} & \\ \text { Mid diameter over bark in cm } & \\ \quad \text { Mean } & 35.7 \\ \quad \text { Min } & 27.6 \\ \quad \text { Max } & 47.2 \\ \text { Top diameter over bark in cm } & \\ \quad \text { Mean } & 33.4 \\ \quad \text { Min } & 25.2 \\ \quad \text { Max } & 43.2 \\ \text { Boards } & \\ n_{\text {board }} & 172 \\ \text { Yield in \% according to DIN } & \\ \text { 4074-1:2012-06 } & \\ \text { S13 } & 5 \\ \text { S10 } & 31 \\ \text { S7 } & 83 \\ \text { Reject } & 53\end{array}$

${ }^{a}$ Only grading criterion DAB was taken into consideration when the boards were visually graded according to DIN 40741:2012-06

Austria) using the software Lignometer. Assuming the transition from juvenile to adult wood at a cambial age of 20 years, the relative juvenile core was possible to calculate dividing the juvenile $\log$ volume by the total log volume. Roblot et al. (2008) pointed out another important reason for the low yield of visual graded Douglas-fir timber, which may be the case for our sample. In their investigation, visual grading for strength provides underestimated strength properties compared with a theoretical grading of an ideal (perfect) grading machine. This kind of machine is able to directly determine the grade determining properties, i.e. bending strength or static bending modulus of elasticity according to EN 408:2010+A1:2012.

In 2012, a sample of 150 logs were transported to Microtec/ Brixen for CT scanning. The study is only focused on those $4.1 \mathrm{~m}$ logs, from which at least four centre boards could be sawn out, in total 36 logs. The logs originated from 20 different trees: 18 butt logs, 11 intermediate logs and 7 top logs. The logs were scanned with the high-speed CT scanner CT Log, produced by Microtec, at $120 \mathrm{~m} / \mathrm{min}$ (Giudiceandrea et al. 2011). CT Log is a tomographic scanner equipped with an X-ray sensor covering a surface of $1478 \mathrm{~mm} \times 752 \mathrm{~mm}$ and an X-ray source at $225 \mathrm{kV}$ and $12 \mathrm{~mA}$. The system produces X-ray slice images which are reconstructed using the Katsevich exact cone beam reconstruction algorithm (Katsevich 2004), obtaining 3D images of the logs with a cross-sectional resolution of $1 \mathrm{~mm}$ and a longitudinal resolution of $10 \mathrm{~mm}$. The image processing software is able to automatically detect many internal features including knots. The knot detection algorithm was developed by
Microtec, based on the work of Johansson et al. (2013), which analyses the concentric surfaces created around the previously extracted pith position. Because of the similarity of the density of the knots and the sound wood in the sapwood, the precision of the estimation of the knots in the side boards is lower.

After sawing, the boards were graded visually according to Table 3 ("Grading rule for boards and planks") of the national German standard DIN 4074-1:2012-06 under laboratory conditions at the Holzforschung München. Detailed knot data was recorded for the entire length of every single board. The standard DIN 4074-1:2012-06 is a widespread visual grading standard in Central and Eastern Europe. Within the standard, a variable called the "DAB" (German abbreviation for "Durchmesser"(diameter), "Astansammlung" (sum of knots), "Brett" (board)) is defined, which is one of the most important grading criterion for the mechanical properties of boards and planks. The DAB - similar to the knot area ratio (KAR) defined in Economic Commission Europe, Food, United Nations (1982) - is a variable that aggregates knot size to judge knot presence in sawn timber and is defined as follows: "The proportion of knots is calculated as the sum of the diameters of all the knots in a region with length $150 \mathrm{~mm}$ (knot cluster) divided by two times the width b (Fig. 1d). Knot dimensions that overlap are considered only once." In Fig. 1d, one can see overlapped knots on the end-grain as dark grey areas. The DAB's main use in Germany is for visually grading lamellas for glued laminated timber. Within this study, only knots were used although the national standard DIN 4074-1:2012-06 provides more grading criterions such as fissures, wane, pith or warp.

Table 1 shows the characteristics of the physical logs and physical boards. The given diameters represent diameters over bark measured with a diameter tape.

\subsection{Validation of knot criterion DAB}

In order to construct the original position of individual boards within the log after sawing, the ends of the logs were marked prior to sawing. The marking consisted of colours sprayed on both ends of each log using a template and a hole drilled on one end of the log. In addition, a plastic tag was fixed to one end of the log for labelling. By comparing the position of the markers in the CT image to their physical position on the sawn boards, a precise common reference between $\mathrm{CT}$ images and sawn boards was calculated, allowing reconstruction of the original position of each board within the log. The logs were sawn with a band saw, during which it was attempted to saw as many centre boards as possible of the preferred cross section of $50 \mathrm{~mm} \times 160 \mathrm{~mm}$, as would be done in a cant sawing system (straight sawing).

Figure $1 \mathrm{a}, \mathrm{b}$ compares the real and the virtual sawing pattern. The red plastic tags used for labelling the logs were also visible in the CT image, and were therefore helpful for the virtual 


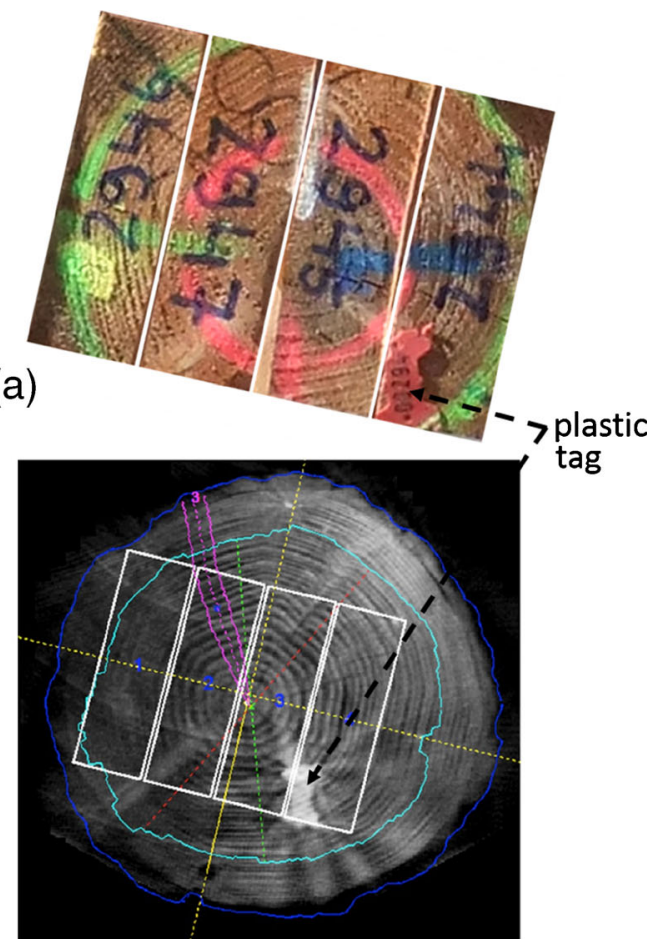

(b)

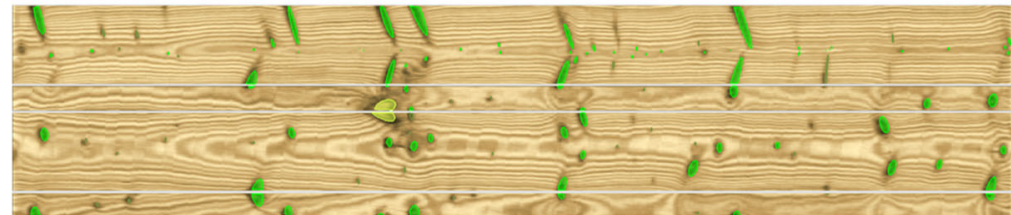

(c)

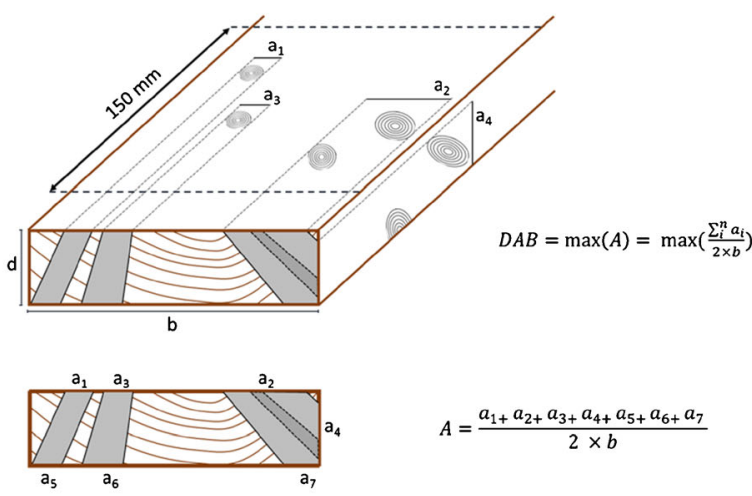

(d)

Fig. 1 Real (a) and virtual (b) cutting patterns at the front side and the four sides of a virtual board (c); the DAB calculation according to the German standard DIN 4074-1:2012-06 for boards and planks (d)

reproduction of the actual sawn pattern. Figure 1c shows the four sides of a virtual board generated by the CT software, with the knots detected by the algorithm highlighted in green.

In our study, the measured variables $\mathrm{DAB}_{\mathrm{CT}}$ and $\mathrm{DAB}_{\text {manual }}$ contain some components of error. For those variables, Legendre (1998) recommends a major axis (MA) regression instead of an ordinary least squares regression. A key assumption of applying ordinary least squares (OLS) is either that the independent variable is measured without error (Harper 2014) or that the magnitude of the error in the response variable is much larger than that on the independent (explanatory) variable (Legendre and Legendre 1988), which is not the case for our analysis. Figure 2 shows the histograms of both the manual

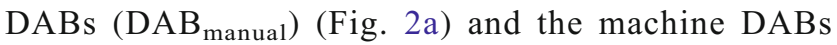
$\left(\mathrm{DAB}_{\mathrm{CT}}\right)$ (Fig. $2 \mathrm{~b}$ ) of the three largest knots per boards, respectively.

\subsection{Optimizing log value using $\mathrm{CT}$ information}

The reference for each log was assumed to be the horns-up position. It was attempted to keep constant all aspects which could influence the results, and only vary the parameters under analysis, namely rotation and price. Cutting pattern, skewness and displacement remained the same for the Monte Carlo simulation. The CT optimization is based on the calculation of the value of the final products, which requires the knowledge of the actual price of the products. As this price depends on the market and therefore vary, three different price scenarios were used (Table 2).

1. For the rotation angles from $1^{\circ}$ to $180^{\circ}$ (with rotation increments of $1^{\circ}$ ), the CT software intersected the boards with the extracted knots, calculated the board grades and applied the different price scenarios (Table 2) to calculate the log value as the sum of the value of the boards.

2. The angle that gives the highest log value was extracted (=optimal angle).

3. In each iteration, a rotation error was drawn from the normal distribution $N\left(0^{\circ}, 5^{\circ}\right)$ (Tulokas and Vuorilehto 2007; Berglund et al. 2014) and added to the optimal angle.

4. In each iteration, a random DAB error was drawn from a normal distribution with mean $=0$ and added to the boards' DABs. The standard deviation was assumed to be equal to the root mean squared error (RMSE) between the machine and modelled DABs.

5. The value of the log calculated with the modified optimal angle and DAB was compared with the value of the log calculated with the horns-up angle and the modified DAB.

The value comparison at steps 3-5 was repeated 1000 times for each log. 

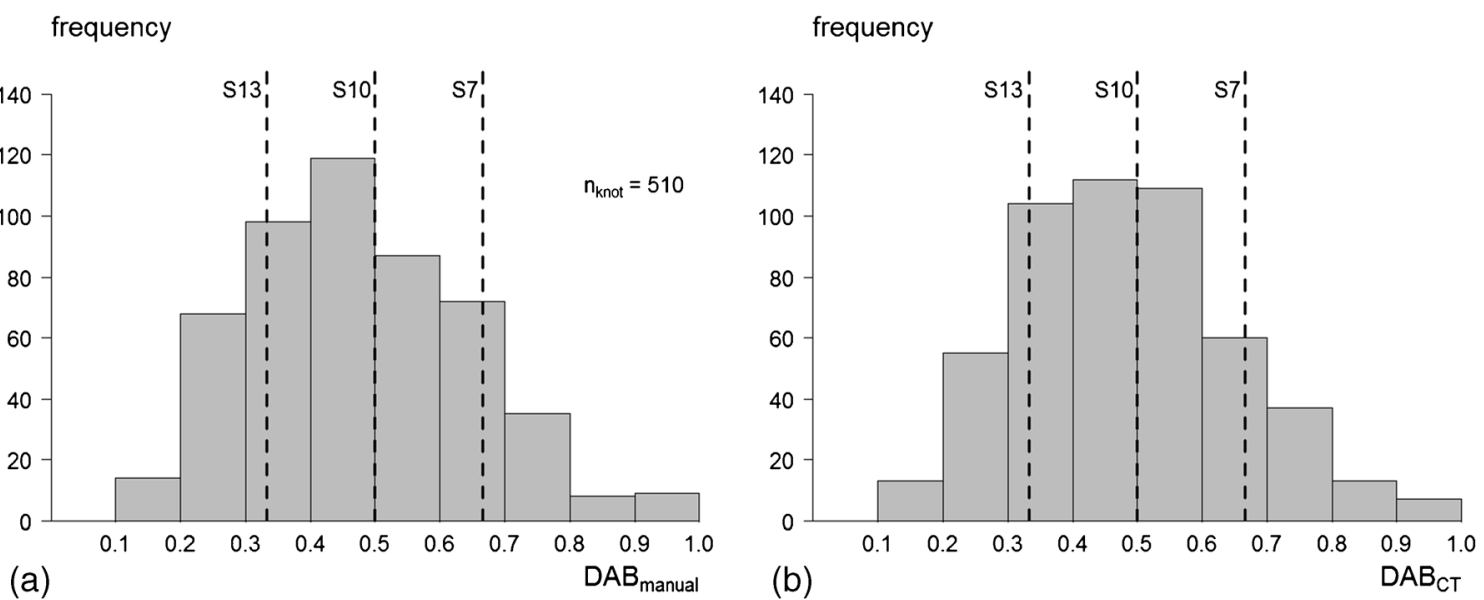

Fig. 2 Histograms of the largest DAB values of all boards both manually (a) and determined by the CT scanner (b). The vertical lines represent the threshold values for the DAB according to the grades S13, S10 and S7 (boards and planks, DIN 4074-1:2012-06)

\section{Results}

Figure 3a compares the three largest DABs of each board detected by the CT with the three largest DABs of each board measured manually. The MA regression line is shown with its 95\% confidence region. The forecasting equation overestimates the machine $\mathrm{DAB}$ value $\left(\mathrm{DAB}_{\mathrm{CT}}\right)$ below the mean and underestimates it above the mean. The $45 \%$ line, which would correspond to perfect forecasting, is also shown for comparison. The residuals are examined versus predicted values (Fig. 3b).

Overall, 510 pairs of $\mathrm{DAB}$ values were investigated, i.e. usually three $\mathrm{DAB}$ pairs per board $\left(n_{\text {board }}=172\right)$; $\mathrm{DAB}$ values less than 0.1 were excluded from the dataset as they are not decisive for strength grading. The light grey, dashed line in Fig. 3a represents the line through the origin. The RMSE is 0.09 . Considering only the first largest $\mathrm{DAB}$ value of each board, the RMSE is 0.10 .

For the sawing optimization, a random error of the DAB measurements was taken with a normal distribution having the mean of zero and a standard deviation of 0.10 .

Figure 4 shows the increase of value for 1000 simulations of all single $\operatorname{logs}$ for price scenario "medium"

Table 2 Relative prices for sawn timber depending on the grades $\mathrm{S} 13$, $\mathrm{S} 10, \mathrm{~S} 7$ and reject

\begin{tabular}{llll}
\hline & $\begin{array}{l}\text { Scenario 1 } \\
\text { "Low" }\end{array}$ & $\begin{array}{l}\text { Scenario 2 } \\
\text { "Medium" }\end{array}$ & $\begin{array}{l}\text { Scenario 3 } \\
\text { "High" }\end{array}$ \\
\hline S13 & 1 & 1 & 1 \\
S10 & 0.95 & 0.9 & 0.8 \\
S7 & 0.9 & 0.8 & 0.6 \\
Reject & 0.7 & 0.5 & 0.2 \\
\hline
\end{tabular}

The grades are defined in the German standard DIN 4074-1:2012-06 for boards and planks (scenario 2 of Table 2). The value increase is relative to a simulated horns-up position. Outliers of the represented boxplots of Fig. 4 are values that are much bigger or smaller than the rest of the data and are represented with a light grey dot. An outlier value was defined as a value that is either larger than third quartile by at least 1.5 times the interquartile range or smaller than the first quartile by at least 1.5 times the interquartile range. In order to determine whether the relative increase of value is above zero or whether the high mean value for the 1000 runs is purely the result of random variation, we used an one-sample $t$-test. A one-sided test (right-tailed test) is suitable because we are specifically interested in knowing whether the relative increase of value is more than zero. The test has the null hypothesis that the mean relative increase of value of a single log (after 1000 runs) is equal to zero, and the alternative hypothesis that the mean relative increase of value of a single log is greater than zero. A significance level of 0.05 is to be used. For all logs, the $p$-values were very low and as a consequence, the null hypothesis was rejected for each log.

Figure 5 illustrates the result of the entire log breakdown simulation for all logs. In more detail, Fig. 5 shows the relative increase of value by rotating the logs to their optimal position prior to sawing. The increase of value is analysed depending on different price scenarios. The average increase (mean value) for all $36 \mathrm{logs}$ and for all 1000 runs was 4,8 and $20 \%$ for price scenario 1 , scenario 2 and scenario 3, respectively (Fig. 5). The medians that are displayed by the boxplots are very similar: 4,8 and $17 \%$, respectively. By means of right-tailed $t$-tests, the null hypothesis that the mean increase of value is equal to zero can be rejected in favour of the alternative hypothesis for a significance level of 0.05 , respectively. The $p$ values are $2.2 \times 10^{-14}, 1.1 \times 10^{-13}$ and $2.8 \times 10^{-12}$ for the low, medium and high price scenarios. 

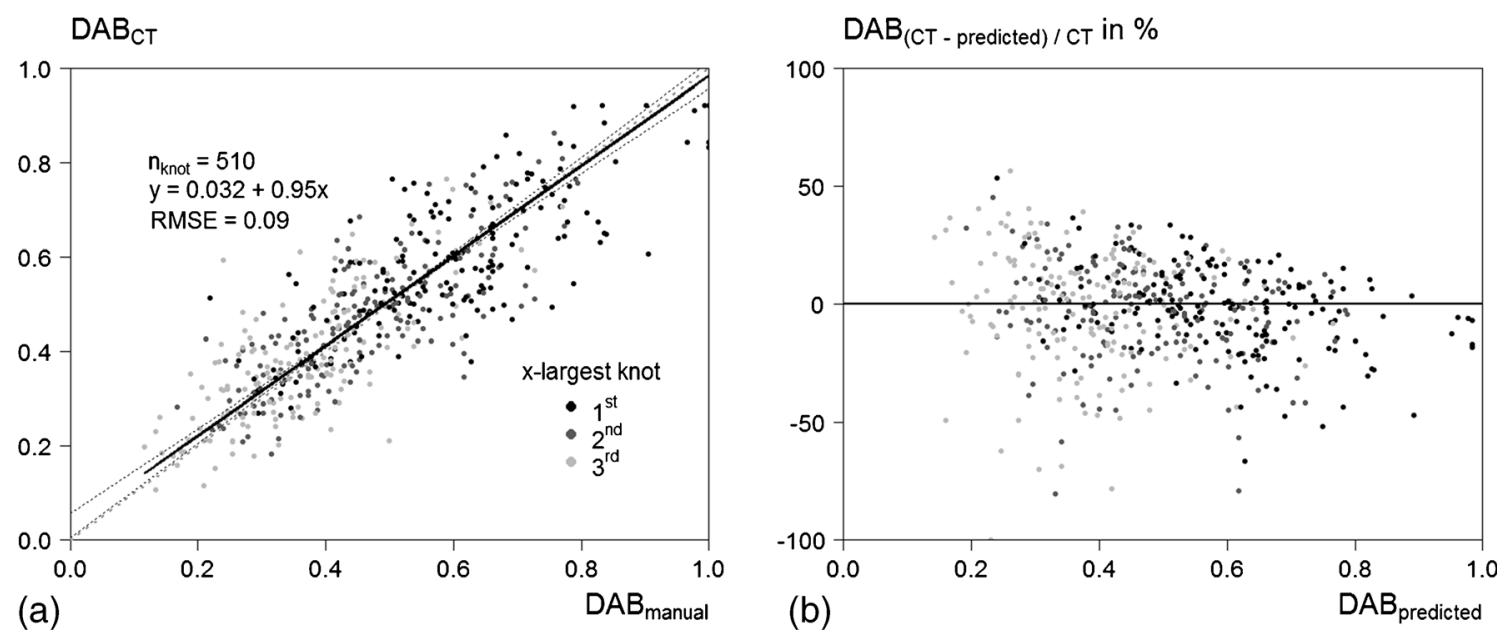

Fig. 3 Scatter diagram of manual $\mathrm{DAB}_{\text {manual }}$ and virtual $\mathrm{DAB}_{\mathrm{CT}}$ detected by the $\mathrm{CT}$ scanner showing the major axis (MA) regression line and its $95 \%$ confidence region; the $45^{\circ}$ dashed line is drawn for reference (a). Relative residuals versus predicted DAB values (b)

\section{Discussion}

The focus of this study was on sawn timber for construction use. Strength grading rules are based on wood characteristics like knots, dynamic modulus of elasticity or wood density because they have a strong relationship to the relevant wood properties strength and stiffness (Bacher 2008). In visual strength grading, the (relative) knot size plays the most important role; in machine strength grading, other important features are the wood density, the grain deviation and the eigenfrequency. The condition of knots (dead or sound) is not decisive, and was therefore not investigated in this study. We did also not focus on whether the knot detection algorithms find all knots or whether the number of knots is given correctly. Instead, we looked mainly at the knot characteristics that determine the grade, as this approach respects the needs of a sawmill requiring prediction of strength and stiffness of the

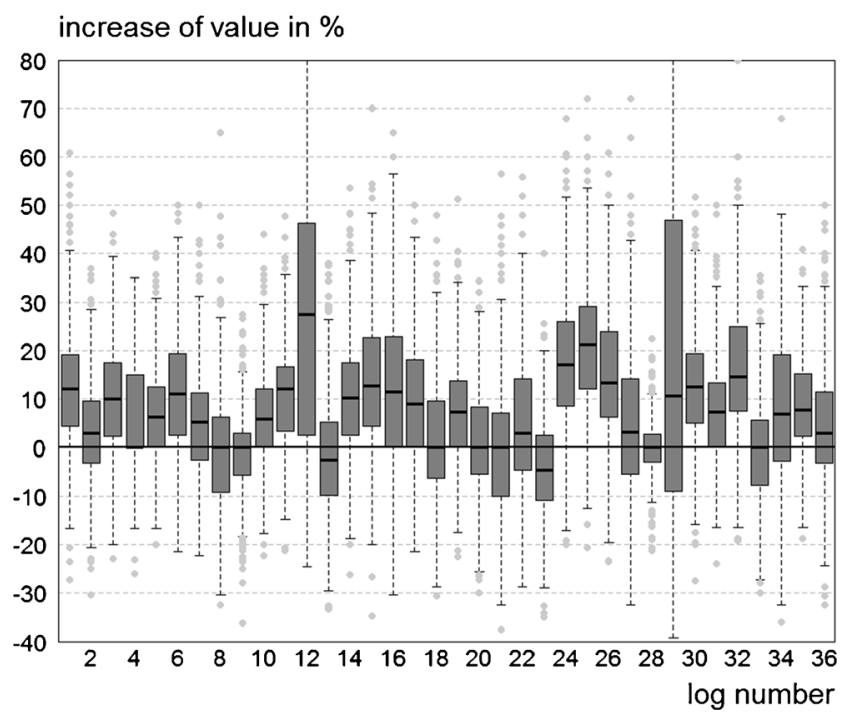

Fig. 4 Relative value increase of all single logs after 1000 runs regarding rotational error and $\mathrm{DAB}$ error sawn product prior to sawing using non-destructive methods. There are other wood features like pith and fissures that determine the grade and can be detected very accurately by the CT (Longuetaud et al. 2004; Wehrhausen et al. 2012). To simplify matters, we did not take those features into account albeit the realistic increase of value can be further maximized.

\subsection{Validation of knot criterion DAB}

One objective of this study was to validate the results of virtual sawing against results of real sawing by means of an industrial CT scanner. Results of previous investigations are based on medical scanners with low scanning speed and high resolutions that lead to stronger relationships between virtual and manual measurements (Longuetaud et al. 2012; Oja 2000; Grönlund 1995). In order to try to overcome this limitation, Johansson et al. (2013) intentionally deteriorated the high

increase of value in \%

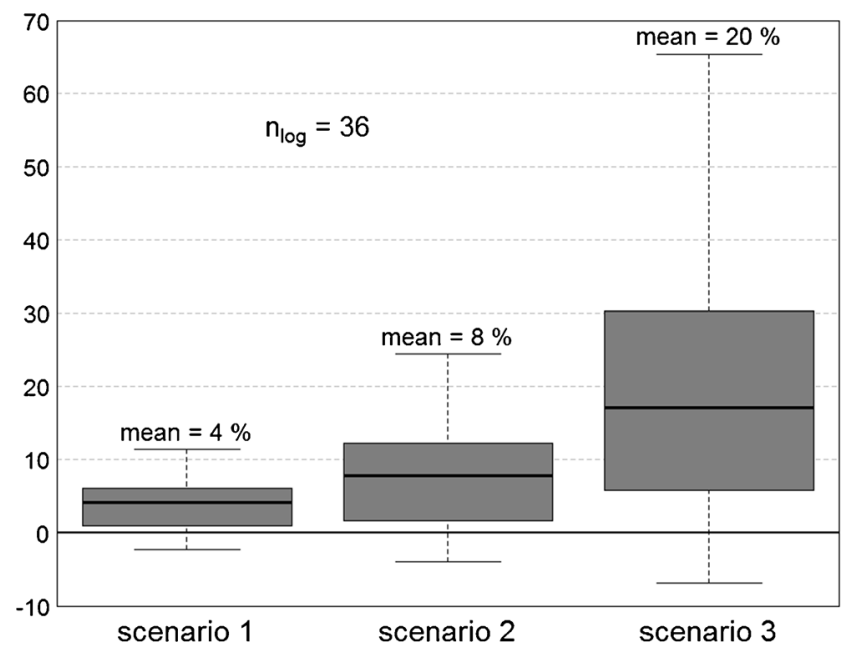

Fig. 5 Mean relative increase of value for all logs depending on different price scenarios after 1000 runs respecting rotational error and DAB error 
quality of the data of a medical CT scanner and so simulated an industrial CT scanner. This analysis used an industrial scanner at industrial speed at $120 \mathrm{~m} / \mathrm{min}$.

A further important point is the choice of the real reference to which the automated measurements are compared. Measurement accuracy was often accomplished by the comparison of the automated measurements to (manual) reference measurements performed on CT images rather than real wood (Longuetaud et al. 2012; Andreu and Rinnhofer 2003; Roussel et al. 2014).

Focusing on those investigations that evaluate and compare real and virtual knot data, the comparison took places at different levels: Johansson et al. (2013) presented the performance of a knot detection algorithm for CT images of logs. They used two different datasets of totally 65 Scots pine and Norway spruce logs coming from the Swedish Stem Bank. The knot features' (knot diameter, knot position, knot end) validation was based on 10 Scots pine $\operatorname{logs}$ and 8 Norway spruce logs. The knot detection algorithm depends on the pith position, bark-wood border and the sapwood-heartwood border, each of which is also detected by an image processing algorithm. The algorithm divides the logs in so-called concentric surfaces (comparable with surfaces of rotary peeled veneers). On these surfaces, all objects that are likely to be knots were fitted to ellipses. Then, knot position - expressed with angular and longitudinal positions as well as order-and size can be calculated. The automatically detected knot diameters and both longitudinal and angular positions of the knot centres were compared to the reference measurements on high-quality CT images. Breinig et al. (2012) made their reference measurements on real (physical) log cross sections spatially corresponding to slices of the $\mathrm{CT}$ images. The knot geometry like width and its radial position were measured on the manual reference cross section and the computer measurement obtained on single CT slices.

Different principles of knot detection between CT and visual strength grading may lead to an increase of inaccuracy and in the RMSE. Knot detection of computed tomography is built up on wood density differences between stem wood and knot wood, whereas manual knot detection is based on differences in colours. The borderline between stem wood and knot wood is not always easy to identify.

It is difficult to obtain exactly the same results from a simulated sawing as from a real sawing at the single log level (Grundberg and Grönlund 1999). One main error occurs in the insufficient description of the real position during the sawing process. For the current analysis, we tried to reproduce the real position by using a template consisting of lines and circles that were sprayed on both end faces. In addition, a hole was drilled in one end face of each log. In addition, fissures at the end faces and a plastic sticker mounted at the end face (visible in Fig. 1b) were also helpful and used. Using all of these markers, we attempted to consider the three types of log positioning: parallel displacement, rotation and skew (Fredriksson 2014).

A further source for the variation is the manual measurement per se. Although the visual grading was done under laboratory condition and therefore is characterized by a much higher accuracy than typical visual grading in a sawmill, the measurements were done by different people. Knot surfaces can be perceived differently from person to person, and it is often difficult to decide where the knots ends and clear wood sections begin. Finally, Nordmark (2003) underlined that the measured sizes of knots had relatively large errors at positions close to the pith.

\subsection{Optimizing log value using CT information}

There are different criterions or references that can be chosen for measuring the benefit (relative increase in value) in breakdown simulations. In literature, the conventional log position is generally defined as the horns-down or horns-up position in particular in terms of optimal volume recovery (Wessels 2009). "Horns-up" describes the position where the plane of maximum log curvature is vertical.

The chosen price scenario also affects the financial benefit of improved sawn timber quality through sawing optimization. Our results are in line with results from previous investigations, in that higher relative price differences between different grades correspond to higher increases in financial benefits (Berglund et al. 2013; Breinig et al. 2013).

The analysis of the increase in value is not based on the theoretical case of perfect sawing execution, but rather with a rotational error and an error in the knot measurement considered. The hypothetical impact of different types of systematic and random errors on value recovery was analysed by Breinig et al. (2013). The reasons for rotational errors are multiple (Vuorilehto and Tulokas 2007). Various rotation precisions can be found in literature. According to an internal report of the Technical Research Centre cited in Tulokas and Vuorilehto (2007), the standard deviation in rotational error must be less than $2^{\circ}$ in order to avoid losing value. A realistic assumption for the standard deviation of current $\log$ rotators is $4^{\circ}$ (Tulokas and Vuorilehto 2007). Berglund et al. (2014) investigated the impact of changing the rotational position on value recovery for Norway spruce. To value the boards, they used Nordic standard INSTA 142 rather than DIN 4074. This standard is of similar relevance for the Scandinavian countries as DIN 4074 is for Central and Eastern Europe. In that study, the average realistic value increase was found to be $6 \%$ with a normally distributed rotation error of $6^{\circ}$ standard deviation and mean of $0^{\circ}$, as opposed to $11 \%$ for the ideal case (no rotation error). The horns-up position was used as the reference. While the price differences were relatively low between the two highest grades and the two lowest grades, there was a steep drop of over $30 \%$ between the two groups. 
In addition to the rotational error, the ongoing analysis included the accuracy of knot size measurement. In the future, however, the realistic increase of value can be even maximized by a more accurate, more powerful and precise log rotation mechanism.

\section{Conclusion}

For the first time, we demonstrate that the use of an industrial $\mathrm{X}$-ray CT scanner can improve significantly the lumber value recovery, thus paving the way for a new generation of sawmilling lines. CT technology is able to optimize value recovery of sawmills by choosing a log rotation angle that produces higher value sawn products than the typical horns-up angle. Depending on the difference between the prices of the different product grades, we obtained an increased sawn product value of between 4 and 20\%. Sawmill owners can therefore benefit from the use of a CT scanner. The impact of CT driven optimization is expected to be even more significant if other possibilities are considered, such as the optimization of the side boards or the selection of sawn products with different dimensions where different quality rules are applied. The CT scanner is also able to detect other internal wood features (pith, fissure, resin and bark pockets, compression wood) that could further increase the value increment of each $\log$.

Acknowledgements We thank the Bavarian State Ministry for Nutrition, Agriculture and Forestry for support of the project "Growth and wood quality of Douglas-fir" (X36). The wood was kindly sponsored by the Bayerischen Staatsforsten, sawn at sawmill Försch/Bavaria, and machine strength graded by Schwörer Haus KG/Germany. Many thanks are also due to the staffs and colleagues of Holzforschung München (TU München), Chair of Forest Growth and Yield Science (TU München) and Microtec for their support. We thank Norvin Laudon for helpful comments and corrections to the English language.

\section{References}

Andreu J-P, Rinnhofer A (2003) Modeling knot geometry in Norway spruce from industrial CT images. In: Bigun J, Gustavsson T (eds) Image analysis. Springer, Berlin, Heidelberg, pp 786-791

Bacher M (2008) Comparison of different machine strength grading principles. In: Proceedings of conference of COST Action E53, 29-30 October, Delft, The Netherlands, 2008. pp 183-193

Berglund A, Broman O, Grönlund A, Fredriksson M (2013) Improved log rotation using information from a computed tomography scanner. Comput Electron Agric 90:152-158. doi:10.1016/j.compag. 2012.09.012

Berglund A, Johansson E, Skog J (2014) Value optimized log rotation for strength graded boards using computed tomography. Eur J Wood Wood Prod 72:635-642. doi:10.1007/s00107-014-0822-8

Brännström M (2009) Integrated strength grading. Luleå University of Technology
Breinig L (2014) CT log scanning for sawing optimization with regard to the aesthetic quality of wood. University of Freiburg

Breinig L, Brüchert F, Baumgartner R, Sauter UH (2012) Measurement of knot width in CT images of Norway spruce (Picea abies [L.] Karst.) - evaluating the accuracy of an image analysis method. Comput Electron Agric 85:149-156. doi:10.1016/j.compag.2012. 04.013

Breinig L, Berglund A, Grönlund A et al (2013) Effect of knot detection errors when using a computed tomography log scanner for sawing control. For Prod J 63:263-274. doi:10.13073/FPJ-D-13-00068

CEN EN 408:2010+A1:2012, Timber structures - structural timber and glued laminated timber-determination of some physical and mechanical properties

Chang SJ, Gazo R (2009) Measuring the effect of internal log defect scanning on the value of lumber produced. For Prod J 59:56-59. doi:10.13073/0015-7473-59.11.56

DIN (2012) DIN 4074-1, Strength grading of wood - coniferous sawn timber

Economic Commission Europe, Food, United Nations, Agriculture Organization of the United Nations (1982) ECE recommended standards for stress grading and finger-jointing of structural coniferous sawn timber

Fredriksson M (2014) Log sawing position optimization using computed tomography scanning. Wood Mater Sci Eng 9:110-119. doi:10. 1080/17480272.2014.904430

Funt BV, Bryant E (1987) Automatic detection of internal log defects by computer interpretation of CT-scan images. For Prod J 37:56-62

Giudiceandrea F, Ursella E, Vicario E (2011) A high speed CT scanner for the sawmill industry. In: Proceedings 17th international nondestructive testing and evaluation of wood symposium, Sopron Hungary, September 14-16, 2011

Grönlund U (1995) Quality improvements in forest products industry. Luleå University of Technology

Grundberg S (1999) An X-ray LogScanner. Luleå University of Technology

Grundberg S, Grönlund A (1999) Validation of a virtual sawmill. In: An X-ray LogScanner - a tool for control of the sawmill process, Grundberg, S., 1999. Doctoral thesis, Luleå University of Technology. pp 207-219

Harper WV (2014) Reduced major axis regression: teaching alternatives to least squares. In: Makar K, De Sousa B, Gould R (eds) Sustainability in statistics education. Proceedings of the ninth international conference on teaching statistics (ICOTS9). Voorburg: International Statistical Institute, Flagstaff, Arizona, USA, pp 1-4

Johansson E, Johansson D, Skog J, Fredriksson M (2013) Automated knot detection for high speed computed tomography on Pinus sylvestris L. and Picea abies (L.) Karst. using ellipse fitting in concentric surfaces. Comput Electron Agric 96:238-245. doi:10.1016/j. compag.2013.06.003

Katsevich A (2004) An improved exact filtered backprojection algorithm for spiral computed tomography. Adv Appl Math 32:681-697. doi: 10.1016/S0196-8858(03)00099-X

Legendre P (1998) Model II regression user's guide, R edition. R Vignette. 14

Legendre P, Legendre L (1988) Numerical ecology, second eng. Elsevier, Amsterdam

Longuetaud F, Leban J-M, Mothe F et al (2004) Automatic detection of pith on CT images of spruce logs. Comput Electron Agric 44:107119. doi:10.1016/j.compag.2004.03.005

Longuetaud F, Mothe F, Kerautret B et al (2012) Automatic knot detection and measurements from X-ray CT images of wood: a review and validation of an improved algorithm on softwood samples. Comput Electron Agric 85:77-89. doi:10.1016/j.compag.2012.03. 013

Lundahl CG, Grönlund A (2010) Increased yield in sawmills by applying alternate rotation and lateral positioning. For Prod J 60:331-338 
Nordmark U (2003) Models of knots and log geometry of young Pinus sylvestris sawlogs extracted from computed tomographic images. Scand J For Res 18:168-175. doi:10.1080/02827580310003740

Nordmark U (2005) Value recovery and production control in the forestry-wood chain using simulation technique. Luleå University of Technology

Oja J (2000) Evaluation of knot parameters measured automatically in CT-images of Norway spruce (Picea abies (L.) Karst.) Holz als Rohund Werkst 58:375-379

Oja J, Grundberg S, Grönlund A (1998) Measuring the outer shape of Pinus sylvestris saw logs with an X-ray LogScanner. Scand J For Res 13:340-347. doi:10.1080/02827589809382993

Rais A, Pretzsch H, Van de Kuilen J-WG (2014a) Roundwood pregrading with longitudinal acoustic waves for production of structural boards. Eur J Wood Wood Prod 72:87-98. doi:10.1007/s00107013-0757-5

Rais A, Van de Kuilen J-WG, Pretzsch H (2014b) Growth reaction patterns of tree height, diameter, and volume of Douglas-fir (Pseudotsuga menziesii [Mirb.] Franco) under acute drought stress in Southern Germany. Eur J For Res. doi:10.1007/s10342-0140821-7

Roblot G, Coudegnat D, Bleron L, Collet R (2008) Evaluation of the visual stress grading standard on French spruce (Picea excelsa) and Douglas-fir (Pseudotsuga menziesii) sawn timber. Ann For Sci 65:812-812. doi:10.1051/forest:2008071

Roussel J-R, Mothe F, Krähenbühl A et al (2014) Automatic knot segmentation in CT images of wet softwood logs using a tangential approach. Comput Electron Agric 104:46-56. doi:10.1016/j. compag.2014.03.004

Stängle SM, Brüchert F, Heikkila A et al (2015) Potentially increased sawmill yield from hardwoods using X-ray computed tomography for knot detection. Ann For Sci 72:57-65. doi:10.1007/s13595-0140385-1

Taylor FW, Wagner FG, McMillin CW et al (1984) Locating knots by industrial tomography - a feasibility study. For Prod J 34:42-46

Tulokas T, Vuorilehto J (2007) Improvement potential in log rotation. Balt For 13:221-228

Vuorilehto J, Tulokas T (2007) On log rotation precision. For Prod J 57: 91-96

Wehrhausen M, Laudon N, Brüchert F, Sauter UH (2012) Crack detection in computer tomographic scans of softwood tree discs. For Prod J 62:434 442. doi:10.13073/FPJ-D-12-00079.1

Wei Q, Leblon B, La Rocque A (2011) On the use of X-ray computed tomography for determining wood properties: a review. Can J For Res 41:2120-2140. doi:10.1139/x11-111

Wessels CB (2009) Cant sawing log positioning optimization: a simulation study. For Prod J 59:17-22 